\title{
DESENVOLVIMENTO HUMANO MUNICIPAL NA REGIÃO DE INTEGRAÇÃO DO BAIXO AMAZONAS EM PERSPECTIVA COMPARADA: UMA ANÁLISE COM VARIÁVEIS PADRONIZADAS
}

\author{
Rhayza Alves Figueiredo de Carvalho ${ }^{1}$ \\ Abner Vilhena de Carvalho ${ }^{2}$ \\ Mario Tanaka Filho ${ }^{3}$ \\ Rodolfo Maduro Almeida ${ }^{4}$ \\ Jarsen Luis Castro Guimarães ${ }^{5}$
}

\section{INTRODUÇÃO}

Mensurar o bem estar e verificar as condições de vida desempenhadas por uma população são extremamente válidos para alcançar os objetivos viver melhor mais feliz e completo além de investigar descompassos existentes entre o quadro existente com o almejado. No contexto mundial essa preocupação ganhou destaque desencadeando uma conceituação de desenvolvimento que nas últimas décadas passou por algumas modificações até chegar ao desenvolvimento humano, onde a ênfase é dada nas pessoas por meio de conquistas legítimas.

Nesse sentido, se discutem os caminhos possíveis para ter acesso a melhores desempenhos socioeconômicos de uma sociedade, e assim, bons desempenhos no nível de desenvolvimento humano. Umas das possibilidades referem-se ao acesso a maiores níveis de renda, pois estes estimulariam melhores de desempenhos em diversos aspectos sociais, tais como educação, cultura, saúde e meio ambiente, podendo ou não ser fundamentados em uma elevação da renda, ou seja, sustentados por essa dimensão.

O desenvolvimento deve ser entendido como um processo de transformação da sociedade, relacionado a mudanças qualitativas significativas, que em geral acontecem de forma cumulativa. Decerto, alterações no nível de expectativa de vida estão associadas a diversas oportunidades sociais que são cruciais como serviços de saúde, desempenho educacional, liberdades políticas que fomentam uma melhor qualidade de vida para a população, mesmo dispondo de baixos níveis de renda, deste modo, a ênfase nesses serviços é válida,

\footnotetext{
${ }^{1}$ Bacharela em Economia pela UFPA. Mestra pelo PPGCS da UFOPA. E-mail: carvalho.rhayza@gmail.com

${ }^{2}$ Doutor em Ciências Ambientais pelo PPGSND da UFOPA. Docente no PCEDR, no PPGCS da UFOPA. E-mail: abnervilhena@hotmail.com

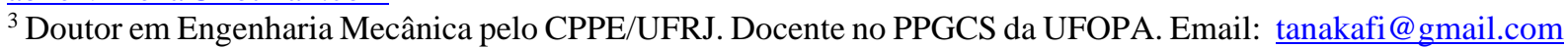

4 Doutor em Computação Aplicada pelo INPE. Docente no PPGCS da UFOPA. E-mail: rodolfomaduroalmeida@gmail.com

${ }_{5}^{5}$ Doutor em Desenvolvimento Sustentável do Trópico Úmido pelo NAEA/UFPA. Docente no PCEDR, no PPGCS e no PPGSND da UFOPA. E-mail: jarsen@bol.com.br
} 
particularmente em economias pobres, na qual essas disposições contribuíram para o crescimento econômico (VEIGA, 2010).

Para que o processo de desenvolvimento seja identificado deve existir harmonia entre os diferentes aspectos sociais, sendo assim, informações sobre a verdadeira situação de localidades são essenciais, como população, economia, meio ambiente dentre outras, para que as autoridades públicas possam construir um planejamento e estratégias visando destacar ou reforçar oportunidades em suas variadas dimensões para a sociedade em geral.

Por essas razões, tanto aspectos qualitativos quanto quantitativos envolvem o processo de identificação da realidade de determinado local, já que alterações no nível de desenvolvimento são considerados qualitativas, enquanto que, no crescimento as mudanças são quantitativas, sendo instrumentos valiosos para referenciar padrões de vida, de modo a identificar comportamentos e reconhecer desdobramentos possíveis.

Nesse sentido, mudanças quantitativas podem gerar melhoras qualitativas, nesse caso, os aumentos nos níveis de renda podem proporcionar impactos positivos nas outras dimensões que envolvem o desenvolvimento humano, como conhecimento e vida longa e saudável, contudo, isso não é uma regra geral, já que existem situações onde as melhoras socioeconômicas não são sustentadas pelo aumento da renda, e sim, pelos demais componentes do desenvolvimento humano que podem impactar diretamente no bem-estar da população.

Em síntese, ao longo dos anos, ocorreram melhorias no nível socioeconômico do País, estados e municípios, revelado principalmente por mudanças positivas no quadro das principais dimensões que envolvem o desenvolvimento humano. Da contextualização apresentada, emerge o seguinte questionamento a ser respondido: Quais os dimensões determinantes para os níveis de desenvolvimento humano alcançados pelos municípios da Região de Integração do Baixo Amazonas (RIBA)?

Apresentando como objetivos: verificar a evolução dos IDHM e suas dimensões nos municípios da RIBA de 1991 para 2010 e, saber o impacto de cada dimensão (renda, educação e longevidade) para formação geral do IDHM nos municípios da Região de Integração do Baixo Amazonas pela análise de regressão, e se o desempenho do IDHM e suas subdimensões tem apresentado melhora ou piora. O intuito do levantamento dessas questões é ajudar a agregar evidências sobre prováveis desigualdades nesta região. 


\section{MEDIDAS DO DESENVOLVIMENTO}

No decorrer dos anos, os esforços para responder as principais questões socioeconômicas ao redor do mundo ocasionou a necessidade de elaboração de medidas, que pudessem ser utilizadas como referências, fornecendo informações sobre o cenário real e proporcionando uma perspectiva comparativa entre as localidades, desta forma um dos frutos do desenvolvimento, o crescimento, foi objeto de descontentamento devido o conceito de crescimento do PIB ser utilizado para mensurar o grau de desenvolvimento social de uma comunidade, apesar de possibilitar verificar o modo como o PIB se distribui na vida das populações, ou seja, de que forma está impactando na qualidade de vida das sociedades, essas informações proporcionam ao poder público instrumento para o planejamento.

Diante disso, no campo dos estudos sociais, foram iniciados grandes esforços de âmbito internacional e nacional por diversas instituições para desenvolver instrumentos visando qualificar e mensurar o bem estar assim como as mudanças sociais, caracterizando um Sistema de Indicadores Sociais, ou seja, um conjunto de indicadores sociais relacionados a uma questão social específica, com intuito de analisar, orientar, acompanhar políticas e contribuir para apontar carências, enriquecendo a interpretação sobre a realidade social (JANUZZI, 2002).

A relevância da construção e manipulação adequada de instrumentos quantitativos que reflitam os fenômenos sociais observados em localidades diversas e causalidades existentes respalda a difusão de tais ferramentas, porém o desafio refere-se justamente na ausência de dados para contemplar dimensões que são difíceis de ser quantificadas com informações adequadas, dessa maneira as pesquisas realizadas com os dados disponíveis, podem ser consideradas ponto de partida para mensurações mais complexas sobre o desenvolvimento.

O indicador social é descrito por Januzzi (2002, p. 54) como "Uma medida em geral quantitativa dotada de significado social substantivo, usado para substituir, quantificar ou operacionalizar um conceito social abstrato, de interesse teórico ou programático".

Com o intuito de analisar a realidade social dos municípios alguns motivos fizeram com que aumentasse a demanda por indicadores sociais por parte do poder público, com diferentes propósitos como subsidiar na elaboração de planos diretores de desenvolvimento e nos planos plurianuais, permitir a avaliação dos impactos ambientais decorrentes da implantação de grandes projetos, para justificar o repasse de verbas federais para implementação de programas sociais dentre outros (JANUZZI, 2009).

Alguns procedimentos estatísticos têm como escopo quantificar fenômenos observados em uma sociedade, principalmente quando acontecem mudanças e oscilações, revelando o 
entendimento e interpretação sobre determinada população em um período. $\mathrm{O}$ uso de um conjunto de dados ocorreu principalmente, por indicadores bem tradicionais como PIB e PIB per capita considerados índices de produção agregada da economia, que surgiram devido a necessidade de mensurar a renda ${ }^{6}$, designando como representativo de uma característica em particular.

A quantificação na pesquisa permitir visualizar, a partir de um conjunto de dados e tratamentos específicos, alguns aspectos que não se revelam em análises primárias. Logo, existem situações em que as grandezas numéricas são essenciais para discussões de temas relevantes para a sociedade, possibilitando mensurar fenômenos em números, de acordo com critérios estabelecidos, portanto, verificar a intensidade de um fenômeno não é algo trivial.

Mourão (2006) afirma que "podemos identificar um indicador como uma estatística, um facto, uma medida, uma série quantitativa de dados (indicador quantitativo) ou uma série de evidências ou percepções postuladas sobre a realidade (indicador qualitativo)”.

Usualmente, o conceito de índice e indicador se confunde, pois ambos funcionam como uma sinalização para manifestar a situação de um sistema determinado, pois são valores estáticos e em grande parte das análises superficiais designam índice e indicador igualmente, portanto são utilizados em grande parte de forma errônea, como sinônimos. Com intuito de facilitar a quantificação, o indicador é uma ferramenta que pode se referir a um dado individual ou um agregado de informações, tendo propósitos específicos (SICHE et al., 2007).

Segundo Mueller et al. (1997) apud Síche et al. (2007) “[...] um bom indicador deve conter os seguintes atributos: simples de entender; quantificação estatística e lógica coerente; e comunicar eficientemente o estado do fenômeno observado".

Para a maioria dos estudiosos a diferença é que o índice revela o valor agregado final de todo um procedimento de cálculo e a correta interpretação da realidade de um sistema simples ou complexo (natural, econômico ou social), utilizando, em seu cálculo, bases científicas e métodos adequados, utilizando-se inclusive, indicadores como variáveis que o compõem, de modo que um índice pode se transformar num componente de outro índice. Enquanto que, o termo indicador é um parâmetro selecionado e considerado isoladamente ou em combinação com outros para refletir sobre as condições do sistema em análise, e possível potencialidade pressagiadora, devido a sua metodologia considerar mudanças internas com o tempo devido alterações de agentes externos ou novos arranjos internos (SICHE et al., 2007).

${ }^{6}$ Além dessa ótica, o PIB pode ser verificado por meio da ótica da produção e despesa (SANDRONI,2007). 
Portanto, os índices e indicadores são instrumentos que podem facilitam na investigação de uma série de acontecimentos presentes e possibilitando construir trajetórias possíveis. Entretanto, o uso indiscriminado dos conceitos de índice e indicador favorece a reprodução de erros analíticos, já que podem ser utilizados como referências entre os pesquisadores.

É importante frisar que o indicador também é um instrumento dinâmico, já que mudanças de conceitos, em escalas temporais e locais também são acompanhadas por alterações nos indicadores propostos para representar determinado processo. Com o intuito de compreender a realidade, os indicadores descrevem uma faceta da mesma, levando em conta a escolha de qual aspecto da realidade será tratado e a definição do conceito abstrato que será utilizado para explicação do fenômeno, assim, definições são as bases para qualquer medida (SOLIGO, 2012).

Algumas variáveis são utilizadas para representar algumas dimensões (sociais, ambientais, políticas e econômicas) que compõem o desenvolvimento, já que envolve uma conceituação dinâmica, e assim, usada como referência para construção de indicadores. A exposição dos valores de determinado conteúdo tem um conjunto de implicações, que vão desde o alarme até punições. Além disso, existem outras nomenclaturas específicas utilizadas nos métodos quantitativos referentes a variáveis analisadas, um exemplo é o PIB per capita, que durante muito tempo foi utilizado como proxy de nível desenvolvimento socioeconômico pelo mundo.

As diferentes áreas do conhecimento tem se empenhado para construir modelos que representem uma simplificação da realidade, bem como a reprodução de uma relação de antecedentes (causas) e consequentes (efeitos) e a estes serem determinísticos, na qual a causa e efeito estão ligadas diretamente, ou estocásticos vinculados indiretamente. Esses aspectos relevantes possibilitam quantificar e associar entre grandezas, por meio do estabelecimento e refinamento, a capacidade de medição em termos de unidades e instrumentos apropriados, contudo não é tarefa fácil (TRZESNIAK, 1998).

\subsection{A MEDIDA “INSUFICIENTE" DO DESENVOLVIMENTO: O PIB E O PIB per capita.}

Durante muito tempo o PIB e o PIB per capita, foram utilizados como parâmetros de diversos aspectos como qualidade de vida, bem estar, desenvolvimento socioeconômico dentre outros, pois o pensamento econômico da época era devoto ao crescimento econômico, na qual acreditava ser um bom indicador e estar altamente correlacionado aos demais indicadores de qualidade de vida. É inegável a importância que tais indicadores revelam ao apresentarem quantificados os níveis de atividades econômicas de uma localidade. 
O PIB é um conceito simples analiticamente e preciso em sua definição. Mensura o crescimento econômico através de transações que possam ser verificadas em valores monetários, e durante muito tempo o crescimento econômico foi sinônimo de desenvolvimento econômico devido à falta de um indicador adequado para mensurar o bem-estar, progresso ou qualidade de vida (FEIJÓ; VALENTE; CARVALHO, 2012).

O principal instrumento para verificar o crescimento de uma economia é o PIB, uma medida que agrega todos os bens e serviços finais produzidos dentro do território econômico de um país, independentemente de nacionalidade dos proprietários das unidades produtoras desses bens e serviços, exclui as transações intermediarias e é medido com valor de mercado, além de indicar a capacidade da economia em gerar postos de trabalho, podendo ser calculado sob três aspectos, o da produção, dispêndio e renda ${ }^{7}$ (SANDRONI, 2007).

Outra proxy ${ }^{8}$ utilizada para medir o crescimento econômico é o PIB per capita. De acordo com Sandroni (2007, p. 641) o PIB per capita "determina a relação econômica estabelecida entre o PIB e a população de um país".

Ressalta-se que, considerando a estrutura dinâmica do crescimento econômico e populacional, e devido tais variáveis se modificam ao longo do tempo, a relação entre elas também varia, dando uma ideia do estágio de desenvolvimento em que se encontra um país. Assim, se o PIB crescer numa taxa superior ao crescimento demográfico, o PIB per capita aumentará, caso contrário, diminuirá e se crescerem na mesma proporção o PIB não se alterará (SANDRONI, 2007).

O PIB per capita é uma referência importante como medida síntese de padrão de vida e desenvolvimento econômico dos países, obtido dividindo-se o PIB do ano pela população residente no mesmo período. Contudo, pode não ser considerado um representante satisfatório do nível de qualidade de vida e consequentemente, do grau de desenvolvimento, apesar de muito utilizado (LIMA; FILHO; PALIS, 2013).

Dentro da teoria econômica o conceito de bem estar foi aplicado tanto na macroeconomia ${ }^{9}$, quanto na microeconomia que trabalhou com o desenvolvimento da Teoria do Bem Estar. Devido a isso, o PIB per capita foi largamente utilizado como medida aproximada de bem estar, apesar de suas limitações. Sofrendo modificações a partir dos anos

\footnotetext{
${ }^{7}$ Pela ótica do produto, mede-se a produção; se for pela ótica da renda, mede-se o rendimento e se for pela ótica da despesa, mede-se o consumo. Todos os agregados se referem ao total da economia, distinguindo-se quanto ao enfoque dos aspectos no processo econômico (LIMA; FILHO; PALIS, 2013).

${ }^{8}$ Refere-se a uma medida aproximada, um indicador (JANNUZZI, 2009).

${ }^{9}$ Ver LIMA; FILHO; PALIS, 2013, p.31
} 
80, com o pensamento associado ao conceito de desenvolvimento, e englobando as dimensões econômica, social e ambiental. E então nos anos 90, as metodologias de indicadores de desenvolvimento humano, ocasionaram as mudanças de ênfase da produção econômica para a mensuração do bem estar dos indivíduos (LIMA; FILHO; PALIS, 2013).

Algumas críticas dirigidas ao PIB referem-se em geral a existência de algumas atividades como o trabalho doméstico, trabalho voluntário, o valor dos serviços ecossistêmicos etc., não são considerados no cálculo do PIB, já que não passam pelo mercado, sendo excluídos. Outro fato é que o PIB não leva em conta a destruição de riqueza, especialmente ambiental, em razão da produção de bens e serviços mercantis, ou seja, contabiliza transações que diminuem ou refletem queda do bem-estar da sociedade, como a degradação ambiental, portanto, o PIB não é um bom indicador do bem-estar das sociedades (FEIJÓ; VALENTE; CARVALHO, 2012).

As contas nacionais de um país apresentam medidas essenciais para aferição da atividade econômica, todavia esses cálculos omitem várias informações que são extremamente válidas para compreensão da dinâmica estrutural de uma sociedade em busca do desenvolvimento, e principalmente, para superar problemas sociais herdados do século passado e persistentes ao longo do tempo, como desemprego, pobreza e desigualdade.

O cálculo desse indicador do crescimento econômico (seja em sua forma agregada - PIB, ou nas demais variantes - PIB per capita, PIB por trabalhador) é efetuado por uma média aritmética e, portanto, o mesmo não indica de que forma a riqueza de um país se distribui entre seus habitantes. Ou seja, a medida do PIB per capita, nada nos informa acerca da desigualdade de renda. Dessa forma, os países podem ter o mesmo PIB per capita com índices de distribuição de riqueza completamente diferentes, de modo que algumas pessoas podem deter grande parte da riqueza e o restante da população pobre ter acesso a apenas uma parte desta, por outro lado, pode não haver extremos tão evidentes, de modo que a riqueza se distribuía de forma mais igualitária entre a maior parte da população (SANDRONI, 2007).

Entretanto, esse histórico foi se modificando ao longo do tempo no tocante ao desenvolvimento, e na década de 90, os estudiosos apresentaram novas conceituações sobre o tema e assim novas formas de mensuração, muito mais condizente com a realidade verificada no mundo, e por isso o PIB se tornou uma medida insuficiente para verificar ao processo complexo atingido pela sociedade na maior parte do globo.

Nesse contexto, uma nova vertente propôs um instrumento quantitativo para integrar uma medida ampliada da conceituação de desenvolvimento, o Índice de Desenvolvimento Humano (IDH), fundamentado no conceito de que as pessoas são a verdadeira riqueza das nações, 
todavia, ainda se mostra insuficiente para responder as inquietações de um conceito complexo e dinâmico, apesar de serem iniciativas relevantes comparativamente às mensurações existentes anteriormente.

\subsection{AMARTYA SEN E O DESENVOLVIMENTO HUMANO}

Existem algumas correntes que defendem seu ponto de vista para o entendimento conceitual de desenvolvimento. São delimitadas três pressuposições epistemológicas, a primeira caracterizando o conceito como multidimensional com escopo social e ético, em que o crescimento econômico é qualificado como instrumental que pode estimular o desenvolvimento, mas não efetivamente garantir, já que este possui objetivos que vão além do simples aumento do PIB, inclusive esse aumento pode ser acompanhado por mazelas como: pobreza, desigualdade e não ampliação emprego, ocasionando externalidades negativas ${ }^{10}$ para a sociedade e sendo considerado como mau desenvolvimento (SACHS, 2008).

Decerto, o desenvolvimento requer a presença da maioria dos segmentos que compõem uma sociedade, de maneira a contribuí-lo e a promovê-lo, assim como, desfrutar de seus resultados, nas quais, autoridades públicas, as instituições, empresas e sociedade civil possam incentivar o planejamento e, portanto, organização desse processo, buscando um equilíbrio de objetivos sociais, ambientais e econômicos entre os atores.

Outra vertente considera o crescimento econômico uma válvula que conduz ao desenvolvimento, considerando um conceito redundante, seguindo um "efeito cascata" (trickle down effect), e defendida pelos fundamentalistas de mercado, em que o desenvolvimento é sinônimo de crescimento econômico. Entretanto, sua principal crítica envolve a falta de igualdade, equidade e solidariedade, já que não eleva níveis sociais determinados para boas condições envolvendo a parte menos favorecida da população, já que é centrada na necessidade de equilíbrio macroeconômico, ou seja, uma vertente particularmente orçamentária, por fim, análises voltadas para oferta de oportunidades de trabalho decente em resposta ao objetivo do desenvolvimento (SACHS, 2008).

Desse modo, o crescimento é entendido como um meio para a promoção do bem-estar social, no qual gerou mudanças passando a ênfase da produção econômica para a mensuração do bem-estar das pessoas, e incluindo além da dimensão econômica, o acesso à educação e a

${ }^{10}$ Ocorre quando a ação de um indivíduo impõe custo sobre terceiros (SANDRONI, 2007). 
serviços de saúde, e assim, o bem estar seria consequência de uma economia financeiramente saudável, socialmente justa e sustentável do ponto de vista ambiental.

Nessa perspectiva, de crescimento como indutor das demais dimensões do desenvolvimento, é imprescindível que maiores acessos aos serviços sociais contribuem diretamente para o bem-estar da sociedade sendo um dos elementos essenciais do desenvolvimento considerado includente sustentável e sustentado (SACHS, 2008).

Dentro dessa vertente economicista redutor, o crescimento pode ser impulsionado por duas vertentes: o custeio público e mediados pelo crescimento. No desenvolvimento conduzido pelo crescimento econômico rápido, os resultados dependem de procedimentos abrangentes, apoiados no emprego e na aplicação da prosperidade econômica na expansão de serviços sociais relevantes (educação, saúde, seguridade social). Em oposição, baseia-se o custeio público, dado pela atuação de um conjunto de serviços de saúde, educação etc., mesmo em circunstancias de lento crescimento, são viabilizados por "trabalho-intensivo", já que em geral, são mais baratos pois os salários são menores comparativamente aos países ricos (VEIGA, 2010).

Essa visão é considerada ultrapassada já que as preocupações atuais vão muito além de uma questão de renda, envolvendo questões multidimensionais, já que na atualidade sabe-se, o desenvolvimento social não deve esperar pelo desenvolvimento econômico. E por fim, a corrente que acredita que o crescimento não é condição necessária nem suficiente para o desenvolvimento, já que melhorias sociais em grande parte das dimensões poderiam ocasionar o desenvolvimento, sem necessariamente serem impulsionadas por um aumento de renda (SACHS, 2008).

Nesse contexto, se destaca a importância do economista indiano Amartya Sem para o cenário mundial que propôs uma visão inovadora e oportuna sobre o desenvolvimento, considerado um processo multidimensional, que levava em conta outras dimensões como social, ambiental, territorial, e política e, não somente as condições econômicas de uma sociedade, colaborando para uma nova compreensão sobre alguns fenômenos sociais, e deixando de buscar caminhos de extremo progresso econômico sem dar atenção às demais dimensões envolvente.

Desta forma, a ênfase passou a ser dada para as pessoas, ou seja, no desenvolvimento humano, uma medida "ampliada" do desenvolvimento, com objetivos de verificar o nível de qualidade de vida das pessoas bem como se os serviços sociais estão adequados, deixando de destacar apenas a questão econômica.

Em meados dos anos 50, alguns países apresentaram intenso crescimento econômico, entretanto, essas elevações não ocasionaram essencialmente maior acesso de populações pobres 
a maiores níveis de educação, saúde, recursos materiais e culturais. Iniciando um intenso debate sobre desenvolvimento, decerto, o papel da renda era essencial, mas, para construção de um quadro social benéfico e igualitário era necessário levar em conta, os êxitos e privações. Desse modo, o desenvolvimento seria observado quando os benefícios do crescimento ampliassem as suas oportunidades e capacidades individuais (VEIGA, 2010).

A reação a todas essas mudanças sociais induziu uma intensa discussão sobre o tema por vários estudiosos das ciências sociais que efetuaram esforços tanto em nível mundial quanto nacional, para investigar e reconhecer as principais dificuldades enfrentadas em cada esfera, e os possíveis rumos para minimizar tais problemas.

Nesse contexto, Amartya Sen reconheceu a necessidade de distintas formas de liberdades para os indivíduos, como ter um padrão de vida digno, longo e saudável, desta forma, combatendo às fontes de privações da liberdade, e aos vários problemas sociais, relacionados com a pobreza econômica, carência de serviços públicos, assistência social, ausência de liberdades políticas e civis, sendo assim, a expansão da liberdade é o principal fim e meio do desenvolvimento, de modo a eliminar fatores limitantes das escolhas e oportunidades individuais (VEIGA, 2010).

Em 1990 ocorreu à publicação do Relatório do Desenvolvimento Humano (RDH) pelo Programa das Nações Unidas para o Desenvolvimento (PNUD) ${ }^{11}$, que buscou findar a ideia que imperava até a década de 70, no qual o desenvolvimento era sinônimo de progresso material (crescimento). Então, o economista paquistanês Mahbud ul Haq juntamente com a colaboração de Amartya Sen e seu pensamento, criaram um indicador sintético com o objetivo de formar um hodômetro do desenvolvimento de um país, já que avaliação e aferição desse processo era uma dificuldade a ser solucionada. Denominado Índice de Desenvolvimento Humano (IDH), de fácil mensuração e simplista, sendo um método alternativo às medidas baseadas tão somente em aspectos econômicos, como o produto interno bruto e a renda per capita, incluindo novas dimensões como de saúde e educação que enriqueceram a noção de desenvolvimento, expondo um novo modo de se entender o desenvolvimento, tornando-se um indicador razoável para este fim (VEIGA, 2010).

Essa nova caracterização de desenvolvimento, assim como, seu instrumento de quantificação, passou a integrar as principais agendas dos países e regiões, com o discurso de

\footnotetext{
${ }^{11}$ Órgão global presente em 177 países e territórios 13 que desenvolve projetos, objetivando contribuir com um crescimento que melhore a qualidade de vida de todos. É também responsável pela elaboração dos Atlas de Desenvolvimento Humano (PREARO; MARACCINI; ROMEIRO, 2014)
} 
fornecer conhecimento mais amplo sobre a realidade agregada em diferentes dimensões de cada localidade.

A abordagem ficou conhecida como desenvolvimento humano como "o processo de ampliação das liberdades das pessoas, no que tange suas capacidades e as oportunidades a seu dispor, para que elas possam escolher a vida que desejam ter" (PNUD; IPEA; FJP, 2013, p. 23). Essa nova vertente também propôs um instrumento quantitativo para integrar essa conceituação, fundamentada no conceito de que as pessoas são a verdadeira riqueza das nações, todavia, ainda se mostra insuficiente para responder as inquietações de um conceito complexo e dinâmico, apesar de serem iniciativas relevantes comparativamente as mensurações existentes anteriormente.

Decerto, o IDH apresenta algumas limitações, porém possibilita demonstrar de maneira clara a distinção entre rendimento e bem estar humano, sendo utilizado como parâmetro de decisão política que avaliar o nível de desenvolvimento nessas dimensões básicas, já que decisões como tais demandam uma mensuração sumária. Outra vantagem dessa medida é possibilidade de verificar o descompasso existente entre nível de renda de determinada comunidade e o padrão social que conseguiu atingir mesmo que revelado somente por escolaridade e longevidade, porém estudos complementares são imprescindíveis para verificar dimensões subjacentes ao desenvolvimento (VEIGA, 2010).

O IDH é um indicador global, dado por três indicadores: de longevidade ${ }^{12}$, educação ${ }^{13} \mathrm{e}$ renda per capita $^{14}$, ampliando o entendimento envolve sobre as responsabilidades dos condutores de política econômica dos países, apesar de não esgotar as necessidades de desenvolvimento humano, classificando assim, os países conforme o nível de bem estar social por meio das dimensões de longevidade, educação e renda. Tal indicador varia de 0 a 1 , sendo calculado por uma média geométrica dos três indicadores base, (desenvolvimento humano total), nas quais, países com IDH até 0,499 têm desenvolvimento humano considerado baixo, os países com índices entre 0,500 e 0,799 são considerados de médio desenvolvimento humano e os países com IDH maior que 0,800 têm desenvolvimento humano considerado alto, classificando assim os países conforme as dimensões (COSTA; ANDRADE; PASA, 2015).

\footnotetext{
${ }^{12}$ Medida em anos representando a expectativa de vida ao nascer.

${ }^{13}$ Combinação de dois indicadores - média de anos de escolaridade e anos de escolaridade esperados, conforme nova metodologia introduzida no RHD de 2010.

${ }^{14}$ Padrão de vida medido pela RNB (em substituição ao PIB per capita, conforme revisão metodológica introduzida em 2010) real em dólares per capita (ou renda per capita) ajustado pelo índice de PPP.
} 
O PNUD Brasil, o Instituto de Pesquisa Econômica Aplicada - IPEA e a Fundação João Pinheiro - FJP assumiram, em 2013, o desafio de adaptar a metodologia do IDH global para calcular o IDH Municipal (IDHM) dos 5.565 municípios brasileiros a partir de dados do Censo Demográfico de 2010. Também recalculou-se o IDHM, a partir da metodologia adotada, para os anos de 1991 e 2000, por meio de uma minuciosa compatibilização das áreas municipais entre 1991, 2000 e 2010 para levar em conta as divisões administrativas ocorridas no período e permitir a comparabilidade temporal e espacial entre os municípios (PNUD; IPEA; FJP, 2013).

Apresentando-se como contraponto ao PIB - abordagem do crescimento econômico puro, “o IDHM populariza o conceito de desenvolvimento centrado nas pessoas, e não a visão de que desenvolvimento se limita a crescimento econômico" (PNUD; IPEA; FJP, 2013, p. 27).

Assim como no IDH global, o IDHM é um número que varia entre 0 e 1 , e, quanto mais próximo de 1, maior o desenvolvimento humano de um município. Para se ler, interpretar e analisar o IDHM 2013, utiliza-se as cinco faixas de classificação, descritas abaixo.

\section{Figura 1: Faixa de Desenvolvimento Humano Municipal}

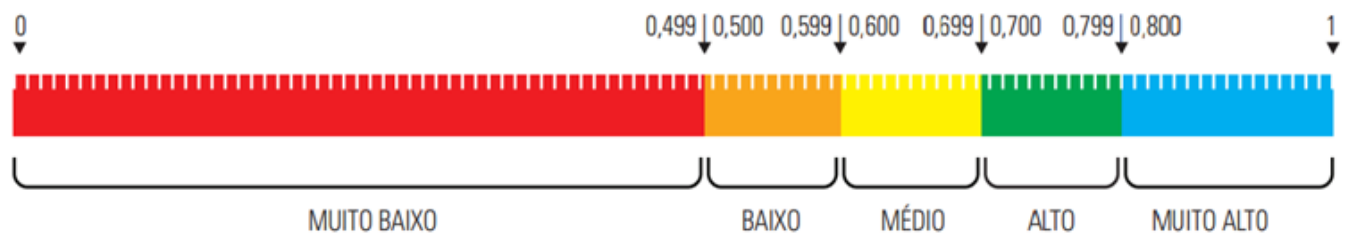

Fonte: (PNUD; IPEA; FJP, 2013, p. 27).

Desse modo, comprova-se a importância em verificar o impacto de cada dimensão para explicar o aumento ou redução geral, e particularmente o descompasso existente entre municípios considerados mais desenvolvidos, pois apresentam boas médias induzidas por um alto indicador de riqueza ao lado dos baixos desempenhos nas outras duas dimensões, considerados atrasados, porém ricos, contrariamente, outros conseguem ter boa qualidade de vida apesar de não serem ricos, e os que se saem bem nas três dimensões assim, como os fracos em todas.

\section{O DELINEMAMENTO E OS ASPECTOS METODOLÓGICOS DA PESQUISA}

A abordagem do estudo é quantitativa no qual foi utilizada a técnica econométrica da análise de regressão múltipla por meio do software Gretl, para testar a validação dos pressupostos clássicos e estimar os coeficientes do modelo de regressão pelo MMQO, o qual estimou o impacto das variáveis que compõem as dimensões do IDHM (educação, longevidade, 
renda). Desse modo, utilizando-se na regressão de variáveis padronizadas a qual favorece comparações em termos, compreendendo a dinâmica dos municipais componentes da Região de Integração do Baixo Amazonas, prevendo o valor de determinadas variável a partir da relação e do comportamento entre elas. Essa modelagem oferece suporte para o planejamento, tomada de decisão e avaliação de políticas públicas, visando principalmente tornar o setor público mais eficiente.

Por sua vez, a abordagem qualitativa foi adotada para dar base e parametrizar os resultados quantitativos, visando a uma melhor análise geral do caso. Quanto à natureza, o trabalho se enquadra em pesquisa aplicada, tendo como interesse a aplicação, utilização e consequências práticas dos conhecimentos.

A metodologia utilizada para realização do presente trabalho é do tipo descritiva, em que é analisada as características da Região de Integração do Baixo Amazonas e o estabelecimento de relações entre variáveis componentes do IDHM, por meio da utilização de técnicas padronizadas de coleta de dados. E a existência de associações entre variáveis, realizada pelo pesquisador preocupado com a atuação prática, constituindo a etapa prévia indispensável para que se possam obter explicações cientificas, utilizando procedimentos de pesquisa de levantamento de uma população, possibilitando o levantamento direto da realidade, economia, rapidez, e obtenção de dados agrupados em tabelas que possibilitam uma riqueza na análise estatística (GIL, 2008).

Na construção do presente estudo trabalhou-se com os dados IDHM e seus componentes: renda, educação, longevidade, para o ano de 1990, 2000 e 2010, do Atlas do desenvolvimento Humano no Brasil para verificar o impacto de cada dimensão para a composição total.

O delineamento da pesquisa é o procedimento adotado para a coleta de dados, é apresentado como pesquisa documental e bibliográfica, pois foram pesquisados livros, artigos e para caracterização do tema desenvolvimento humano, como também relatórios das Nações Unidas e organismos internacionais como o Banco Mundial. A coleta de dados deu-se por fontes primárias são "dados históricos, bibliográficos e estatísticos; informações, pesquisas e material cartográfico; arquivos oficiais e particulares; registros em geral; documentação pessoal etc.” e fontes secundárias que são "imprensa em geral e obras literárias", Fez-se a revisão da literatura para dar suporte ao desenvolvimento do tema. 


\subsection{DESCRIÇÃO DO INSTRUMENTAL ANÁLITICO: A REGRESSÃO MÚLTIPLA COM VARIÁVEIS PADRONIZADAS}

A modelagem econométrica é uma representação matemática que enriquece as análises realizadas para verificar simulações de impacto, comparações de objetivos, possibilitando uma melhor inferência sobre a realidade estudada. A modelagem econômica é uma construção teórica que descreve, a partir de hipóteses de comportamento e por meio de equações formais, relações entre duas ou mais variáveis. De acordo com LIMA; FILHO; PALIS (2013, p. 2) “[...] essas relações, quando testadas empiricamente, geram um resultado que estima o valor de uma ou mais variáveis, ou simula efeitos de mudanças nas variáveis de resultado".

Sabemos que "as unidades em que o regressando e regressor(es) estão expressos afetam a interpretação dos coeficientes de regressão. Isso pode ser evitado se nós dispusemos a expressar regressando e regressor como variáveis padronizadas" (GUJARATI, 2006, p. 140).

A padronização das variáveis é realizada subtraindo o valor da média da variável de seus valores individuais e dividindo-se a diferença pelo desvio padrão dessa variável, conformo descrição a seguir, adaptada de Gujarati (2006):

$$
Y_{i t}^{*}=\frac{Y_{i t}-\bar{Y}}{S_{Y}} \quad X_{i t}^{*}=\frac{X_{i t}-\bar{X}}{S_{X}},
$$

Onde: $\bar{Y}=$ média amostral de $\mathrm{Y} ; S_{Y}=$ desvio-padrão amostra de $\mathrm{Y} ; \bar{X}=$ média amostral de $\mathrm{X}$; $S_{X}=$ desvio-padrão amostra de $X ; Y_{i t}^{*}$ e $X_{i t}^{*}$ são as chamadas variáveis padronizadas.

Cabe ressaltar que, "uma propriedade interessante das variáveis padronizadas é que sua média é sempre zero e seu desvio-padrão é sempre igual a um. Em consequência, não importa em que unidades se expressem o regressando e os regressores (GUJARATI, 2006, p. 140).

De posse das variáveis padronizadas, podemos calcular a regressão em termos destas variáveis, sob a seguinte forma:

$$
Y_{i t}^{*}=\beta_{o}^{*}+\beta_{1}^{*} X_{1 i t}^{*}+\beta_{2}^{*} X_{2 i t}^{*}+\beta_{3}^{*} X_{3 i t}^{*}+\varepsilon_{i t}^{*}
$$

Numa regressão envolvendo regressando e regressor(es) padronizados, o termo de intercepto sempre será zero, e os coeficientes de regressão são conhecidos na literatura como coeficientes beta (GUJARATI, 2006; 2011). Portanto, os coeficientes beta da regressão equação (2) representam:

$\beta_{1}^{*}$ : o coeficiente que mede o impacto da variável $X_{1 i t}^{*}$ em $Y_{i t}^{*}$, em termos de desvio-padrão. $\beta_{2}^{*}$ : o coeficiente que mede o impacto da variável $X_{2 i t}^{*}$ em $Y_{i t}^{*}$, em termos de desvio-padrão. $\beta_{3}^{*}$ : o coeficiente que mede o impacto da variável $X_{3 i t}^{*}$ em $Y_{i t}^{*}$, em termos de desvio-padrão. 
Ou seja, se regressor padronizado $\left(X_{1 i t}^{*}\right)$ aumenta em 1 desvio-padrão, em média, o regressando padronizado $\left(Y_{i t}^{*}\right)$ aumenta em $\beta_{1}^{*}$ unidades de desvio-padrão. A vantagem do modelo padronizados em relação ao modelo tradicional fica mais aparente quando há mais de um regressor, que é o caso deste estudo, o qual apresenta 3 (três) regressores, pois conforme descreve Gujarati (2006):

\begin{abstract}
Ao padronizar os regressores, estamos pondo todos eles em uma mesma base e podemos assim, compará-los diretamente. Se o coeficiente de um regressor padronizado forma maior que o de outro regressor padronizado que conste do mesmo modelo, então ele contribui mais em relação à explicação do regressando do que o segundo. Em outras palavras, podemos usar os coeficientes beta como medida da força relativa dos vários regressores (GUJARATI, 2006, p. 141).
\end{abstract}

Dessa forma, ao estimar os coeficientes da equação de regressão estaremos medindo o efeito não em termos das unidades originais em que $Y$ e os $X$ 's foram expressos, mas em unidades de desvio-padrão.

\title{
3.2 CARACTERIZAÇÃO/EVOLUÇÃO DAS VARIÁVEIS E A APRESENTAÇÃO/DISCUSSÃO DOS RESULTADOS EMPÍRICOS
}

De acordo com a Fundação Amazônia de Amparo a Estudos e Pesquisas (2017), a Região de Integração do Baixo Amazonas é composto por treze ${ }^{15}$ municípios, tais como: Alenquer, Almeirim, Belterra, Curuá, Faro, Juruti, Mojuí dos Campos, Monte Alegre, Óbidos, Oriximiná, Prainha, Santarém e Terra Santa.

Em 2014 a área aproximada da Região de Integração do Baixo Amazonas era em torno de 315,86 mil km², o que corresponde a $25 \%$ da área total do Estado do Pará, e sua população equivalia a 770.275 habitantes. As atividades econômicas que possuem destaque na região são as que se relacionam com a mineração, o agronegócio, a agricultura familiar e o turismo, sendo que este último tem como base principal o turismo ecológico, uma vez que a mesorregião possui muitos atrativos naturais, como praias e belas paisagens (BRASIL, 2012).

Utilizando-se os dados censitários disponibilizados no Atlas do Desenvolvimento Humano (ADH) nos anos de 1991, 2000 e 2010, baseado nos valores do IDHM e seus respectivos índices dimensionais disponíveis para os municípios que formam a RIBA, foram

\footnotetext{
${ }^{15} \mathrm{O}$ município de Mojuí dos campos foi integrado à região do Baixo Amazonas no ano de 2012, e por isto não foi incorporado nas análises do estudo.
} 
estimados os valores do IDHM e das suas respectivas dimensões conforme informações apresentadas na Tabela abaixo:

Tabela 1- Evolução do IDHM e suas dimensões em termos absolutos.

\begin{tabular}{ccc|c|c|c|c} 
TERRITÓRIO & ANO & IDHM & $\begin{array}{c}\text { IDHM } \\
\text { renda }\end{array}$ & $\begin{array}{c}\text { IDHM } \\
\text { longevidade }\end{array}$ & $\begin{array}{c}\text { IDHM } \\
\text { educação }\end{array}$ \\
\hline \multirow{2}{*}{ RIBA } & 1991 & 0,3257 & 0,4656 & 0,6171 & 0,1273 \\
& 2000 & 0,4500 & 0,4934 & 0,7068 & 0,2656 \\
& 2010 & 0,5985 & 0,5588 & 0,7752 & 0,4963 \\
\hline
\end{tabular}

Fonte: Elaboração dos Autores com base nos dados do ADH (2013).

De forma geral, percebe-se elevações tanto no valor do índice geral (IDHM), como nas demais dimensionais que o compõem (renda, longevidade e educação), no período 1991, 2000 e 2010. Embora, deva enfatizar que a dimensão de longevidade apresentou os maiores valores absolutos, enquanto que a subdimensão de educação, o pior. Para auxiliar na compreensão da evolução do IDHM, e de seus respectivos subíndices (renda, longevidade e educação) verificase o gráfico abaixo.

Gráfico 1- Evolução do IDHM e suas Dimensões em termos Absolutos.

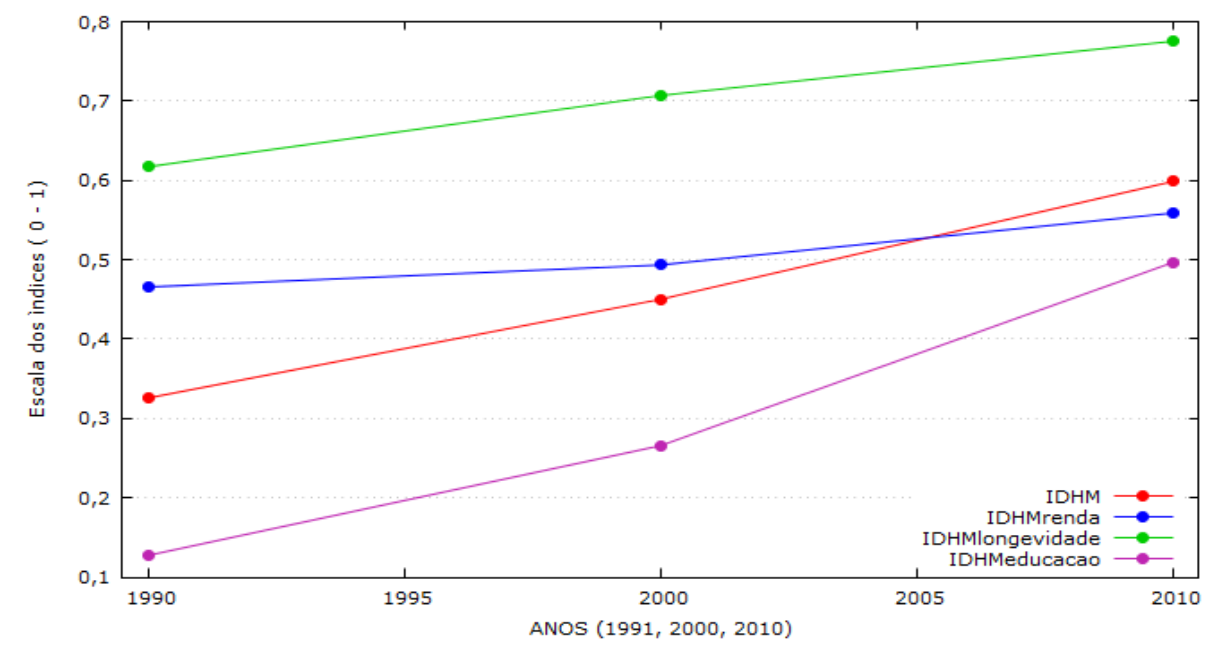

Fonte: Elaboração dos Autores com base nos dados ADH (2013) com uso do Gretl.

A figura acima demonstra que a dimensão longevidade está acima da média do IDHM da RIBA e a dimensão educação abaixo da média do IDHM do RIBA.

Ainda analisando a evolução do IDHM e das suas dimensões foi descrito na tabela a seguir os valores das variações entre os três períodos. De forma geral, tanto o IDHM, como suas dimensões desagregadamente apresentaram variação positiva nos três períodos. 
Tabela 2 - Evolução do IDHM e suas Dimensões em termos percentuais.

\begin{tabular}{c|c|c|c|c|c} 
TERRITÓRIO & ANO & IDHM & IDHM renda & $\begin{array}{c}\text { IDHM } \\
\text { longevidade }\end{array}$ & $\begin{array}{c}\text { IDHM } \\
\text { educação }\end{array}$ \\
\hline \multirow{3}{*}{ RIBA } & $\Delta(2000-1991)$ & 0,3818 & 0,0598 & 0,1454 & 1,0857 \\
& $\Delta(2010-2000)$ & 0,3300 & 0,1326 & 0,0967 & 0,8688 \\
& $\Delta(2010-1991)$ & 0,8378 & 0,2003 & 0,2562 & 2,8979 \\
\hline
\end{tabular}

Fonte: Elaboração dos Autores com base nos dados do ATH (2013).

Ressalta-se que a subdimensão de educação, do IDHM apresentou a maior variação percentual, de aproximadamente, $289,79 \%$, portanto, a maior variação ao longo do período. Enfatiza-se que, ao importar os dados ao software estatístico foram encontradas variáveis nãonuméricas para as variações $(\Delta)$ das dimensões do IDHM - renda, longevidade e educação. As variáveis receberam códigos numéricos, para cada temporalidade da variação conforme mostrado na tabela a seguir:

Tabela 3 - Codificação para a $\Delta$ das variáveis das Dimensões do IDHM.

\begin{tabular}{c|c}
\hline Código Numérica da Variação Temporal & Temporalidade da Variação $(\Delta)$ \\
\hline 1 & '2000-1991' \\
2 & '2010-2000' \\
3 & '2010-1991' \\
\hline
\end{tabular}

Fonte: Elaboração dos Autores com base nos dados do ADH (2013) com uso do Gretl.

Após a codificação numérica da variação temporal da base dados, gerou-se o gráfico 2, que apresenta a evolução comparativa da variação percentual do IDHM e da dimensões do IDHM, em termos percentuais, correspondente a RIBA.

Destaca-se que, no gráfico, a escala descrita no eixo vertical (ordenada) ao lado esquerdo, representa a evolução percentual das dimensões renda e longevidade e; a escala descrita no eixo da vertical (ordenada) ao lado direito, representa a evolução percentual do IDHM total e da dimensão de educação.

Gráfico 2- Evolução Comparativa da $\Delta$ do IDHM e das dimensões do IDHM em termos Percentuais 


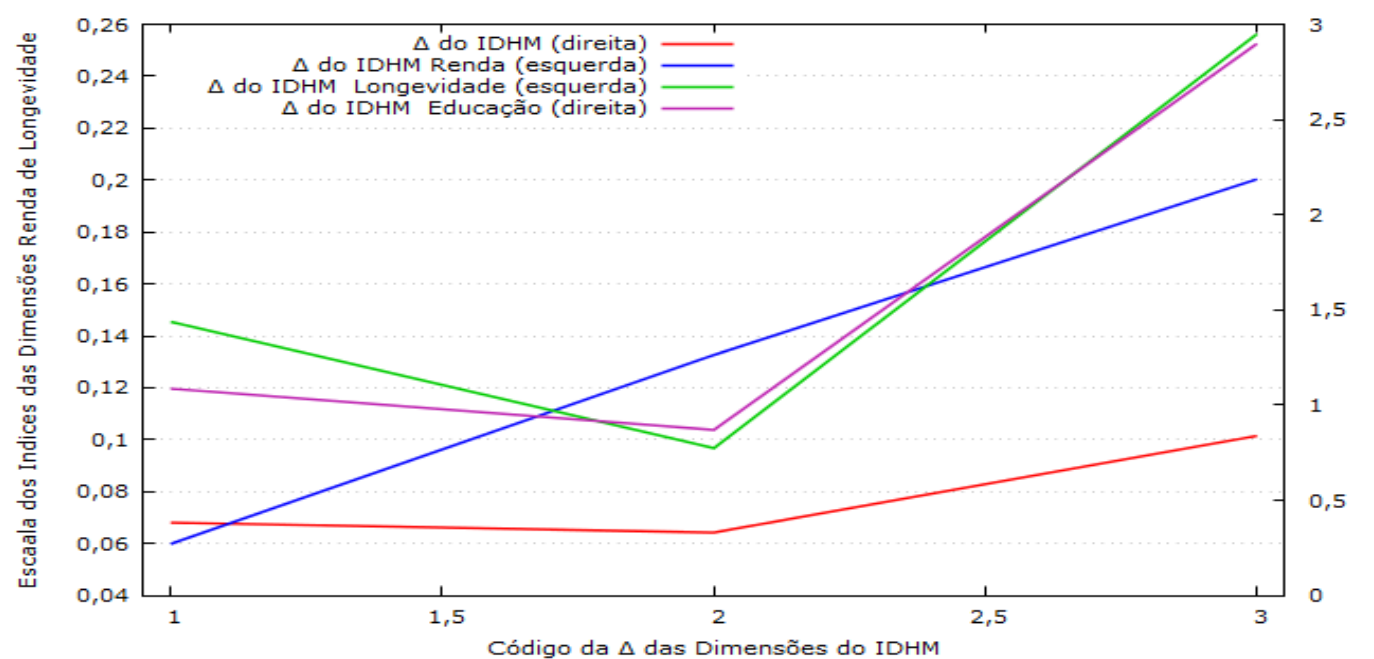

Fonte: Elaboração dos Autores com base nos dados do Atlas do Desenvolvimento Humano (2013) com uso do software Gretl.

Considerando os três pontos de variação percentual, apresentados na tabela 3, equivalente aos períodos de '2000-1991' - código 1; período '2010-2000' - código 2 e; período '2010-1991' - código 3, observa-se que, com base na figura acima, que apenas a dimensão renda do IDHM apresentou variação crescente entre os períodos, destaca-se o IDHM educação e longevidade (linha roxa e verde) com desempenhos semelhantes, tendo variações decrescentes no primeiro momento, seguido de variações crescentes.

Na tabela 4, estão resultados do teste de Jarque-Bera para normalidade das variáveis:

Tabela 4- Teste de Normalidade das Variáveis.

\begin{tabular}{c|c|c}
\hline INDICADOR & Teste de Jarque-Bera & p-valor \\
\hline IDHM & 1,45488 & 0,483143 \\
IDHMRENDA & 1,34827 & 0,509597 \\
IDHMLONGEVIDADE & 2,61681 & 0,270251 \\
IDHMEDUCACAO & 2,47759 & 0,289733 \\
\hline
\end{tabular}

Fonte: Elaboração dos Autores com base nos dados do ADH (2013) com uso do Gretl.

Tomando por base as hipóteses $\mathrm{H}_{0}$ : $\mathrm{O}$ erro tem distribuição normal e $\mathrm{H}_{\mathrm{a}}$ : $\mathrm{O}$ erro não se distribui normalmente e, ainda baseado na tabela 4 , observa-se que o valor de $p>\alpha$, indicando não ser possível concluir que os dados seguem uma distribuição normal, ou seja, se o valor de $p$ for maior do que o nível de significância, $\alpha$, deve-se rejeitar a hipótese nula. Neste caso, não há evidências suficientes para concluir que os dados seguem uma distribuição normal.

Abaixo, na tabela 5 encontra-se a matriz de correlação de Pearson para os dados do IDHM e de suas respectivas subdimensões, considerando $5 \%$ valor crítico (bicaudal) $=0,3291$ para $n=36$ observações $(i=12$ e $t=3)$. 
Tabela 5- Matriz de Correlação do IDHM com os Índices de Dimensão.

\begin{tabular}{c|c|c|c|c}
\hline & IDHM & IDHM & IDHM & \\
IDHM & RENDA & LONGEVIDADE & EDUCAÇÃO & INDICADORES \\
\hline 1,0000 & 0,7953 & 0,9201 & 0,7953 & IDHM \\
& 1,0000 & 0,7191 & 0,7188 & IDHM RENDA \\
& & 1,0000 & 0,8912 & IDHM LONGEVIDADE \\
& & & 1,0000 & IDHM EDUCACAO \\
\hline
\end{tabular}

Fonte: Elaboração dos Autores com base nos dados do Atlas do Desenvolvimento Humano (2013) com uso do software Gretl.

Usamos o termo correlação positiva quando $\mathrm{r}>1$, e nesse caso à medida que $\mathrm{X}$ cresce também cresce $\mathrm{Y}$, e correlação negativa quando $\mathrm{r}<1$, e nesse caso à medida que $\mathrm{X}$ cresce, $\mathrm{Y}$ decresce (em média). Quanto maior o valor de r (positivo ou negativo), mais forte a associação. No extremo, se $r=1$ ou $r=-1$ então todos os pontos no gráfico de dispersão caem exatamente numa linha reta. No outro extremo, se $r=0$ não existe nenhuma associação linear.

A forma de avaliação do coeficiente de correlação, segundo Callegari-Jacques (2003 apud Lira, 2004, p. 54), segue que "se $0,00<\rho^{\wedge}<0,30$, existe fraca correlação; se $0,30 \leq \rho^{\wedge}<0,60$, existe moderada correlação; se $0,60 \leq \rho^{\wedge}<0,90$, existe forte correlação; se $0,90 \leq \rho^{\wedge}<1,00$, existe correlação linear muito forte".

Portanto, com base nas relações da tabela 5, a existência de correlação positiva entre o IDHM (dos municípios do RIBA) e suas respectivas dimensões. O valor $\rho^{\wedge}$ do coeficiente de correlação e o grau (intensidade) da associação entre as variáveis apresentaram-se da seguinte maneira:

a) Existência de forte correlação entre o IDHM e as dimensões de renda, educação e longevidade, pois em todas aquelas associações, o valor do coeficiente de correlação apresentou-se no intervalo de $0,60 \leq \rho^{\wedge}<0,90$.

b) Existência de correlação muito forte entre o IDHM e a dimensão longevidade, pois o valor do coeficiente de correlação que representa o grau da associação linear entre as variáveis, apresentou-se no intervalo de $0,90 \leq \rho^{\wedge}<1,00$.

O gráfico de dispersão é utilizado para pontuar dados em um eixo vertical e horizontal com a intenção de exibir quanto uma variável é afetada por outra, além de ser importante para se verificar a estabilidade na distribuição dos dados (GUJARATI, 2006; 2011). Abaixo estão as dispersões das subdimensões em relação ao IDHM, utilizadas no modelo. 
Gráfico 3- Dispersão do IDHM em relação as Dimensões do IDHM.

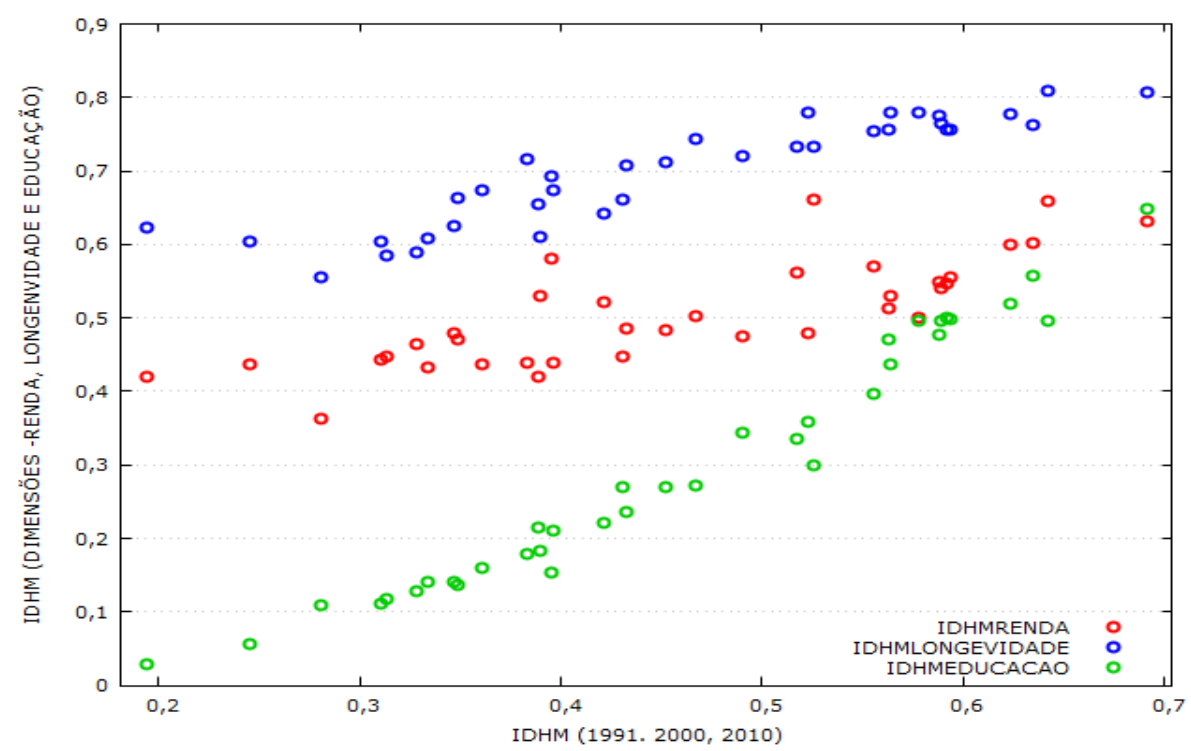

Fonte: Elaboração dos Autores com base nos dados do Atlas do Desenvolvimento Humano (2013) com uso do software Gretl.

A análise da dispersão, disposta no gráfico, confirma a forte correlação positiva entre os valores crescentes do IDHM associados aos valores crescentes das dimensões.

\section{RESULTADOS DA ESTIMAÇÃO DA REGRESSÃO E OS TESTES DOS PRESSUPOSTOS BÁSICOS DO MODELO}

A modelagem econométrica seguindo a descrição: modelo de regressão padronizada com parâmetros estimados pelo método dos mínimos métodos quadrados ordinários (MMQO) tendo o Índice de Desenvolvimento Humano (IDHM) como variável dependente e as dimensões: Renda do Índice de Desenvolvimento Humano (IDHMRenda), Longevidade do Índice de Desenvolvimento Humano (IDHMlongevidade) e, Educação do Índice de Desenvolvimento Humano (IDHMeducação) como as variáveis explicativas do modelo.

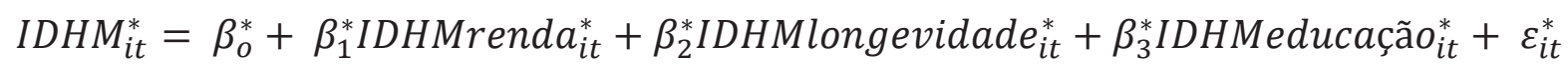

Onde:

$\beta_{0}=\alpha=$ intercepto;

$I D H M_{i t}^{*}=$ Índice de Desenvolvimento Humano padronizado do município $i$ no tempo $t$;

IDHMrenda $a_{i t}^{*}=$ Índice de Desenvolvimento Humano padronizado da dimensão renda do município $i$ no tempo $t$;

IDHMlongevidade ${ }_{i t}^{*}=$ Índice de Desenvolvimento Humano padronizado da dimensão longevidade do município $i$ no tempo $t$. 
IDHMeducação $o_{i t}^{*}=$ Índice de Desenvolvimento Humano da dimensão padronizado educação do município $i$ no tempo $t$

$\beta_{o}^{*}=$ termo de intercepto da regressão.

$\beta_{1}^{*}=$ coeficiente beta $1 ; \mathrm{i}=$ municípios $(1, \ldots, 12) ; \mathrm{t}=\operatorname{anos}(1991,2000$ e 2010$)$.

$\beta_{2}^{*}=$ coeficiente beta $2 ; \mathrm{i}=$ municípios $(1, \ldots, 12) ; \mathrm{t}=\operatorname{anos}(1991,2000$ e 2010$)$.

$\beta_{3}^{*}=$ coeficiente beta $3 ; \mathrm{i}=$ municípios $(1, \ldots, 12) ; \mathrm{t}=\operatorname{anos}(1991,2000$ e 2010$)$.

$\varepsilon i t=$ termo erro estocástico.

Os resultados da estimação do modelo de regressão deste estudo estão dispostos na tabela abaixo:

Tabela 6- Resultados do MMQO e Teste da Significância das variáveis do Modelo

\begin{tabular}{c|c|c|c}
\hline VARIÁVEIS EXPLANATÓRIAS & IDHMrenda $i t^{*}$ & IDHMlongevidade it* & IDHMeducação it ${ }^{*}$ \\
\hline Coeficientes & 0,160524 & 0,165517 & 0,717204 \\
(Erro Padrão) & $(0,0343191)$ & $(0,0525769)$ & $(0,0525991)$ \\
$\mathrm{T}$ & 4,677 & 3,148 & 13,64 \\
p-valor & $5,06 \mathrm{e}-05 * * *$ & $0,0035 * * *$ & $7,05 \mathrm{e}-015 * * *$ \\
\hline
\end{tabular}

Fonte: Resultados do Gretl com base nos dados dos Censos Censitários.

Coeficientes das variáveis explicativas significantes à $* 0,10 \mathrm{p} ; * * 0,05 \mathrm{p}$ e $* * * 0,01 \mathrm{p}$.

Estimando o modelo de regressão múltipla pelo Método dos Mínimos Quadrados Ordinários (MMQO), apresenta a seguinte equação de regressão estimada:

$$
\begin{aligned}
I D H M_{i t}^{*}= & 0,0000+0,160524 \text { IDHMrenda } a_{i t}^{*}+0,165517 \text { IDHMlongevidade }_{i t}^{*}+ \\
& 0,717204 \text { IDHMeducação } o_{i t}^{*}+\varepsilon_{i t}^{*}
\end{aligned}
$$

É importante atentar para os sinais dos coeficientes beta da regressão, pois todos apresentaram sinal positivo ao coeficiente. Ou seja, quando um indicador variar de forma positiva, este influência de forma também positiva na variação do outro indicador. Portanto, a estimação dos coeficientes da equação (3), com base nos seus parâmetros beta indicaram evidências de que as três dimensões do IDHM (renda, longevidade e educação) tem contribuído de forma geral para o aumento do IDHM no período analisado.

As interpretações dos coeficientes beta's sugeriram que se os indicadores (IDHMs padronizado) das dimensões renda, longevidade e educação, aumentarem de 1 (um) desviopadrão, em média, o IDHM aumentará em cerca de 0,160, 0,165 e 0,717 de desvio, respectivamente. Contudo, apesar das três dimensões (renda, longevidade e educação) impactarem positivamente para a formação do IDHM, percebe-se que a dimensão educação apresentou maior efeito em termos de desvio-padrão, de aproximadamente $72 \%$, ao passo que as demais dimensões - renda e longevidade - apresentaram efeitos muito próximos em termos de desvio, ambos de, aproximadamente, $16 \%$. Portanto, de forma geral, a dimensão educação é 
a que menos tem contribuído para a formação do indicador sintético IDHM, no período analisado.

Apresenta um Intervalo de confiança (IC) para os coeficientes da regressão ( $\beta_{1}, \beta_{2} \mathrm{e}$ $\left.\beta_{3}\right)$ para $95 \%$ de nível de confiança $(\mathrm{C}=1-\alpha)$ e 1\% de nível de significância (de margem de erro, $\alpha)$, com 34 graus de liberdade $(\mathrm{Gl}=\mathrm{n}-\mathrm{k}=36-2=34)$. Empregando a distribuição $\mathrm{t}$ de student, na qual o valor crítico de $\mathrm{t}-\mathrm{t}$ tabelado $(\mathrm{t} \alpha / 2)$ correspondente equivale $\mathrm{t}(34,0,005)$ $=2,728$. Portanto, estabeleceu-se os seguintes IC's :

i) $\quad$ IC para o coeficiente $\beta_{0} \rightarrow \operatorname{Pr}[-0,0623943 \leq 0,000000 \leq 0,0623943]=0,99$

ii) $\quad$ IC para o coeficiente $\beta_{1} \rightarrow \operatorname{Pr}[0,0215362 \leq 0,165517 \leq 0,254506]=0,99$

iii) $\quad$ IC para o coeficiente $\beta_{2} \rightarrow \operatorname{Pr}[0,0215362 \leq 0,165517 \leq 0,309498]=0,99$

iv) $\quad$ IC para o coeficiente $\beta_{3} \rightarrow \operatorname{Pr}[0,573162 \leq 0,717204 \leq 0,861245]=0,99$

Então, dado o coeficiente de confiança de $99 \%$, no longo prazo, em 99 de cada 100 casos, os intervalos acima dispostos conterão os verdadeiros $\beta_{1}, \beta_{2}$ e $\beta_{3}$.

O teste de significância individual para as variáveis do modelo, considerando o $t$ crítico com $99 \%$ de nível de confiança e 1\% de margem de erro e, considerando também as seguintes hipóteses: $\mathrm{H}_{0}: \beta_{1}=\beta_{2}=\beta_{3}=0$ e $\mathrm{H}_{1}: \beta_{1}=\beta_{2}=\beta_{3} \neq 0$,

Com 34 graus de liberdade, percebe-se, com base na Tabela 1, que todas variáveis explicativas do modelo são significante ao nível de $99 \%$ confiança, pois para todas as variáveis, a estatística $\mathrm{t}_{\text {calculado }}>\mathrm{t}_{\text {tabelado }}\left(\mathrm{t} \beta_{1}=4,677 ; \mathrm{t} \beta_{2}=3,148\right.$ e $\left.\mathrm{t} \beta_{3}=13,64>\mathrm{t}_{\text {tabelado }}=2,728\right)$. Logo rejeita a hipótese nula, concluindo que todas as variáveis explicativas do modelo - IDHMrenda, IDHMlongevidade e IDHMeducação, são estatisticamente significativas para explicar a variável dependente, IDHM a um nível de significância $\leq 1 \%$.

Para testar a significância global do modelo, foram utilizados os testes do R2 e o Teste F, e seu respectivo p-valor. Os resultados destes testes podem ser observados na tabela abaixo:

Tabela 7- Testes de Significância Global do Modelo 2 pelo MMQO

\begin{tabular}{c|c}
\hline Testes & Valores da Estimação \\
\hline $\mathrm{R}^{2}$ & 0,982913 \\
$\mathrm{R}^{2}$ Ajustado & 0,981312 \\
$\mathrm{~F}(2,34)$ & 613,6047 \\
P-valor (F) & $2,42 \mathrm{e}-28$ \\
\hline
\end{tabular}

Fonte: Resultados do Gretl com base nos dados dos Censos Censitários.

$\mathrm{Na}$ análise da significância global do modelo, pelo critério do $\mathrm{R}^{2}=0,982913$, ou seja, podemos afirmar que, aproximadamente $98,29 \%$ das variações na variável dependente - IDHM 
são explicadas pelas variáveis independentes do modelo: IDHMRenda, IDHMlongevidade e IDHMeducação.

Testando a significância pelo critério do teste F, para F tabelado em $99 \%$ de margem de confiança e $1 \%$ de margem de erro, e considerando também F de Significância: $F(2,34)=$ 613,6047 e P-valor $(F)=2,42 \mathrm{e}-28$, cujas hipóteses são: $\mathrm{H}_{0}: \beta_{1}=\beta_{2}=\beta_{3}=0$ e $\mathrm{H}_{1}: \beta_{1}=\beta_{2}=\beta_{3} \neq$ 0 .

Considerando, o F calculado $(2329,204)$ é maior que F tabelado $(8,52228)$, logo rejeitase a hipótese nula, o modelo é estatisticamente significativo para explicar a variável dependente, a um nível de significância de $\leq 1 \%$.

Para testar a violação dos pressupostos básicos do modelo da regressão foram utilizados os seguintes testes: normalidade dos resíduos, não linearidade (quadrados), especificidade pelo critério Ramsey/Reset (apenas quadrado), heterocedasticidade - pelo critério de White e autocorrelação - pelo critério de Durbin-Watson. Os resultados calculados no modelo, para aqueles testes, estão descritos na Tabela 7, abaixo:

Tabela 7- Resultados dos Testes de Violação dos Pressupostos do MMQO

\begin{tabular}{c|c}
\hline TESTE & p-valor \\
\hline Normalidade & $2,2367 \mathrm{e}-009$ \\
\hline Não-Linearidade (quadrados) & $3,28842 \mathrm{e}-006$ \\
\hline Especificidade Ramsey/Reset & $1,05172 \mathrm{e}-008$ \\
\hline Teste de White para a heteroscedasticidade & 0,0389111 \\
\hline Autocorrelação - Durbin-Watson & 0,0260177 \\
\hline
\end{tabular}

Fonte: Resultados do Gretl com base nos dados dos Censos Censitários.

Assim, valida-se a análise com as estimativas dos parâmetros adequadamente.

\section{CONSIDERAÇÕES FINAIS}

$\mathrm{Na}$ perspectiva do desenvolvimento humano os resultados mostraram que tanto para o IDHM geral, quanto para as subdimensões renda, longevidade e educação ocorreram aumentos nos valores absolutos. Os dados desagregados - por dimensões do IDHM, confirmam as disparidades sociais existentes entre os municípios, e evidenciam que os melhores resultados estão nos municípios com maiores níveis de renda per capita.

Essa pesquisa apresenta uma procedimentos metodológicos valiosos pois verifica o impacto de cada dimensão componente do IDHM, em termos de desvio padrão, de modo a investigar se a distribuição dos valores observados tendem a estar mais distantes ou menos do valor total (IDHM) e assim, averiguar qual dimensão que tem o maior impacto para a composição do IDHM total, de maneira a ajudar na diminuição deste e do seu nível de 
desenvolvimento, a metodologia utilizada tem caráter inovador, já que os trabalhos nesses sentido são mínimos.

Desta forma, com base nos parâmetros beta's calculados na regressão efetuada, foi verificado um impacto positivo por parte de todas as dimensões componentes do IDHM (renda, longevidade e educação) no período analisado. Porém, considerando que esse valor do parâmetro mede o impacto em termos de desvio padrão, assim sendo, quanto maior o valor do parâmetro estimado, menor é o impacto desta na formação do valor total do IDHM.

Logo, a dimensão de educação apresentou impacto em termos de desvio-padrão, de aproximadamente $72 \%$, ou seja, foi a que menos contribuiu para formar o valor total do Índice de Desenvolvimento Humano Municipal, dessa maneira, essa dimensão necessita de uma maior atenção, principalmente de ações governamentais que visem melhorar os níveis educacionais na Região de Integração do Baixo Amazonas, e assim, todas as dimensões contribuam de modo harmônico para formar um desenvolvimento humano satisfatório.

Essa análise colabora no direcionamento da ênfase que deve ser dada a dimensão que apresenta maior impacto na composição do índice total, no sentido de guiar para formulação de políticas públicas principalmente na dimensão mais dispersa, e que estrategicamente pode ser priorizada, já que pode ser a principal responsável pelo falta de harmonia entre as dimensões, e assim de um bom desempenho do Índice de Desenvolvimento Humano Municipal.

\section{REFERENCIAS BIBLIOGRÁFICAS}

BRASIL. Relatório Analítico do Território do Baixo Amazonas - Pará. Ministério de Desenvolvimento Agrário - $\quad$ MDA, 2012. Disponível em:<http://sit.mda.gov.br/download/ra/ra018.pdf>. Acesso em 16 junho de 2017.

COSTA, J.; ANDRADE, J. R. de; PASA, L. A. Visualização e análise de dados dos índices de desenvolvimento humano (IDHM) dos municípios do Rio Grande do Norte usando mapas de kohonen. In: CONGRESSO, 12th CONTECSI International Conference on Information Systems and Technology Management. USP, May 20/22 São Paulo: 2015.

FEIJÓ, C. A.; VALENTE, E.; CARVALHO, P. G. M. Além do PIB: uma visão crítica sobre os avanços metodológicos na mensuração do desenvolvimento socioeconômico e o debate no Brasil contemporâneo. Revista Estatística e Sociedade, Porto Alegre, n. 2, p. 42-56, nov. 2012. GUJARATI; D. N. Econometria Básica. 4 ed. Rio de Janeiro: Elsevier- Campus, 2006. GUJARATI, D. N.; PORTER, D. C. Econometria Básica. 5 ed. Porto Alegre: RS, 2011. 
GIL, A. C. Métodos e técnicas de pesquisa social. 5. ed. São Paulo: Atlas, 2007.

JANUZZI, P. de M. Considerações sobre o uso, mau uso e abuso dos indicadores sociais na formulação e avaliação de políticas públicas municipais. Revista de Administração Pública, Rio de Janeiro, v. 36, n. 1, p. 51-72, jan./fev. 2002.

Indicadores socioeconômicos na gestão pública. Florianópolis: Departamento de

Ciências da Administração / UFSC, Brasília: CAPES: UAB, 2009. 112p. Disponível em:< http://biblioteca.virtual.ufpb.br/files/pub_1291088256.pdf >. Acesso em: 09 mar. 2018.

LIMA, F. C. G. de C., FILHO, N. H. B.; PALIS, R. Agregados macroeconômicos e identidades contábeis. In: C. A. F.; R. L. O. R. (Org.). Contabilidade social: a nova referência das contas nacionais do Brasil, 4. ed. Rio de Janeiro: Elsevier, 2013.

LIRA, S. A. Análise de correlação: abordagem teórica e de construção dos coeficientes com aplicações. Dissertação (Mestrado) - Curso de Pós Graduação em Métodos Numéricos em Engenharia dos Setores de Ciências Exatas e de Tecnologia, Universidade Federal do Paraná. Curitiba, 2004.

MOURÃO, P. R. Contributo para o estudo económico dos indicadores regionais. Revista Portuguesa de Estudos Regionais, Portugal, v. 1, n. 12, 2006.

PARÁ. Baixo Amazonas. Fundação Amazônia de Amparo a Estudos e Pesquisas. FAPESPA. Disponível em: $<$ http://www.fapespa.pa.gov.br/produto/estatisticamunicipal/67>. Acesso em: 16 jun. 2017.

PREARO, L. C.; MARACCINI, M. C.; ROMEIRO, M. do C. Fatores determinantes do Índice de Desenvolvimento Humano dos Municípios do Estado de São Paulo. Revista Brasileira de Políticas Públicas, Brasília, v. 5, n. 1, p. 137-155, 2015.

PNUD; IPEA; FJP. Atlas do Desenvolvimento Humano. Brasília: PNUD Brasil, 2003.

- Atlas do Desenvolvimento Humano no Brasil. 2013. Brasília: PNUD Brasil. Disponível em: <www.atlasbrasil.org.br>. Acesso em: 11 set. 2018.

Atlas do Desenvolvimento Humano no Brasil. IDHM, Municipal, 2000 e 2010.

Brasília: PNUD $\quad$ Brasil, 2013. Disponível <http://www.atlasbrasil.org.br/2013/pt/consulta/>. Acesso em: 15 set. 2018.

SACHS, I. Desenvolvimento: Includente, Sustentável, Sustentado. Rio de Janeiro: Garamond, 2008.

SANDRONI, Paulo. Dicionário de Economia do século XXI. Record, 2007.

SICHE, R. et al. Índices versus indicadores: precisões conceituais na discussão da sustentabilidade de países. Ambiente e Sociedade. São Paulo, v.10, n.2, p.137-148, 2007.

SOLIGO, V. Indicadores: conceito e complexidade do mensurar em estudos de fenômenos sociais. Estudos em Avaliação Educacional, São Paulo, v. 23, n. 52, p. 12-25, mai./ago. 2012. TRZESNIAK, P. Indicadores quantitativos: reflexões que antecedem seu estabelecimento. Ciência da Informação, Brasília, v. 27, n. 2, p. 159-164, 1998. Disponível em: <http://www.scielo.br/pdf/ci/v27n2/2729808.pdf>. Acesso em: 28 abr. 2011.

VEIGA, J. E. da. Desenvolvimento sustentável: o desafio do século XXI. Rio de Janeiro: Garamond, 2010.

Recebido em Janeiro de 2020.

Aceito para Publicação em Junho de 2020. 


\title{
DESENVOLVIMENTO HUMANO MUNICIPAL NA REGIÃO DE INTEGRAÇÃO DO BAIXO AMAZONAS EM PERSPECTIVA COMPARADA: UMA ANÁLISE COM VARIÁVEIS PADRONIZADAS
}

\author{
Resumo \\ O presente estudo visa investigar o impacto das dimensões - renda, educação e longevidade - \\ que compõem o Índice de Desenvolvimento Humano Municipal (IDHM) na formação do \\ IDHM na Região de Integração do Baixo Amazonas (RIBA), com o propósito de contribuir na \\ discussão e fomento de políticas públicas voltadas para as dimensões que menos impactaram a \\ composição do valor do IDHM, assim como, verificar a evolução e comportamento daquele \\ índice e suas dimensões na RIBA. Utilizou-se do instrumental econométrico para fazer a \\ modelagem de mensuração de impacto, com os dados de IDHM padronizados na estrutura de \\ painel curto, disponibilizados pelo Atlas do desenvolvimento humano, correspondentes aos \\ períodos censitários de 1991, 2000 e 2010. Dentre os principais resultados, destaca-se que a \\ dimensão Educação do IDHM foi a que menos impactou na composição do IDHM geral da \\ RIBA, revelando um impacto de 0,74 - em termos de desvio-padrão igual a 1 , ou seja, esta foi \\ a dimensão que menos contribui para a formação daquele índice. Muito embora, em termos \\ absolutos de IDHM médio, a dimensão Educação tenha apresentado uma evolução \\ relativamente inferior as outras dimensões, renda e longevidade, contudo, em termos de \\ variação percentual, o IDHM Educação, foi o que mais evoluiu no período analisado. \\ Palavra-Chave: Renda. Longevidade. Educação. Desenvolvimento. RIBA.
}

\section{MUNICIPAL HUMAN DEVELOPMENT IN THE LOWER AMAZON REGION OF INTEGRATION IN COMPARATIVE PERSPECTIVE: AN ANALYSIS WITH STANDARDIZED VARIABLES}

\begin{abstract}
The present study aims to investigate the impact of the dimensions - income, education and longevity - that compose the Municipal Human Development Index (IDHM) in the formation of the HDI in the Region of Integration of the Lower Amazon (RIBA), with the purpose of contributing to the discussion and promotion of public policies focused on the dimensions that least impacted the composition of the value of the HDI, as well as to verify the evolution and behavior of that index and its dimensions in the RIBA. We used the econometric instruments to perform the impact measurement modeling with the standardized HDI data in the short panel structure provided by the Atlas of human development, corresponding to the census periods of 1991, 2000 and 2010. Among the main results, it is worth noting that the Education dimension of the HDI was the one that had the least impact on the composition of the RIBA's general HDI, showing an impact of 0.74 - in terms of standard deviation equal to 1 , that is, for the formation of that index. Although, in absolute terms of the average HDI, the Education dimension presented a relatively lower evolution of the other dimensions, income and longevity, however, in terms of percentage variation, the HDI Education, was the one that evolved the most during the analyzed period.
\end{abstract}

Keyword: Income. Longevity. Education. Development. RIBA. 